\title{
Non-steroidal anti-inflammatory drug use does not appear to be associated with increased cardiovascular mortality in patients with inflammatory polyarthritis: results from a primary care based inception cohort of patients
}

\author{
N J Goodson, ${ }^{1,2,3}$ A M Brookhart, ${ }^{2}$ D P M Symmons, ${ }^{3}$ A J Silman, ${ }^{3}$ D H Solomon ${ }^{2}$
}

\begin{abstract}
Academic Rheumatology Unit, University Hospital Aintree, Liverpool University, Liverpool, UK; ${ }^{2}$ Division of

Pharmacoepidemiology, Brigham and Women's Hospital, Harvard Medical School, Boston,

Massachusetts, USA; ${ }^{3}$ ARC Epidemiology Unit, Manchester University, Manchester, UK
\end{abstract}

Correspondence to: Dr N Goodson, Academic Rheumatology Unit, University Hospital Aintree, Liverpool University, Lower Lane, Liverpool, L9 7AL, UK: ngoodson@liverpool.ac.uk

Accepted 3 April 2008 Published Online First 13 April 2008

This paper is freely available online under the BMJ Journals unlocked scheme, see http:// ard.bmj.com/info/unlocked.dtl

\section{ABSTRACT}

Objectives: There is controversy about the effects of non-steroidal anti-inflammatory drugs (NSAIDs) on cardiovascular disease (CVD) mortality. The aim of this study was to explore associations between NSAID use and mortality in patients with inflammatory polyarthritis (IP). Subjects and methods: A total of 923 patients with new onset (IP), recruited to the UK Norfolk Arthritis Register (NOAR) between 1990-1994, were followed up to the end of 2004. Current medication was recorded annually for the first 6 years and then every 2-3 years. Rheumatoid factor (RF) and C-reactive protein (CRP) were measured. Logistic regression was used to calculate all cause and CVD mortality odds ratios (OR) for NSAID use at baseline and during follow-up, adjusting for gender and time-varying covariates: RF, CRP, joint counts, smoking, steroid use, DMARD use and other medication use.

Results: By 2004 there were 203 deaths, 85 due to CVD. At baseline, NSAIDs were used by $66 \%$ of patients. In final multivariate models, baseline NSAID use was inversely associated with all cause mortality (adjusted $\mathrm{OR}$ $0.62,95 \% \mathrm{Cl} 0.45$ to 0.84 ) and CVD mortality (adjusted OR $0.54,95 \% \mathrm{Cl} 0.34$ to 0.86$)$. Interval NSAID use had weaker mortality associations: all cause mortality (adjusted OR 0.72, 95\% Cl 0.52 to 1.00 ), CVD mortality (adjusted hazard ratio (HR) $0.66,95 \% \mathrm{Cl} 0.40$ to 1.08).

Conclusion: No excess CVD or all cause mortality was observed in NSAID users in this cohort of patients with IP. This is at variance with the literature relating to NSAID use in the general population. It is unclear whether this represents unmeasured confounders influencing a doctor's decision to avoid NSAIDs in the treatment of IP.

Patients with rheumatoid arthritis (RA) experience increased rates of myocardial infarction and death from cardiovascular disease (CVD) when compared to the general population. ${ }^{12}$ The reasons for this increased CVD mortality and morbidity in association with chronic inflammatory joint disease is currently the subject of much research. Chronic inflammation may contribute to the progression of atherosclerosis in these patients. ${ }^{3}$ Reduction of inflammation by use of disease-modifying antirheumatic drugs (DMARDs) may be associated with reduced rates of CVD events in RA. ${ }^{4-6}$ However, other medications commonly used in the treatment of inflammatory arthritis may adversely affect the cardiovascular system.
There is great interest in the CVD side-effects of non-selective non-steroidal anti-inflammatory drugs (NSAIDs) and selective cyclo-oxygenase-2 (COX2) inhibitors. It is accepted that these drugs have the potential to increase CVD risk, in the general population, by increasing systolic blood pressure $^{7}$ and exacerbating existing congestive heart failure ${ }^{8}$ and there is concern over the thrombotic potential of highly selective COX2 inhibition. Use of the non-selective NSAID, naproxen, was associated with reduced rates of CVD events in patients with $\mathrm{RA}^{9}{ }^{10}$ and metaanalysis of observational studies has suggested a CVD protective association with naproxen. ${ }^{11} 12$ There is little evidence for a primary cardiac protective effect of other non-selective NSAIDs in the general population.

Patients with chronic inflammatory polyarthritis (IP) use NSAIDs for symptom control, often over long periods of time and usually in combination with DMARDs. Given that patterns of NSAID use may be different in this patient group than in the general population, the aim of this study was to explore whether NSAID use was associated with cardiovascular mortality in patients who have IP.

\section{METHODS}

\section{Study population}

This study utilised data from the Norfolk Arthritis Register (NOAR). ${ }^{13}$ This is a primary care based inception cohort of patients who presented with signs and symptoms of IP. Patients with synovitis affecting two or more peripheral joints, lasting for $\geqslant 4$ weeks are eligible for assessment. Patients are visited in the home setting by a research nurse who conducts a structured interview, recording prescribed medications and patient use of over the counter (OTC) drugs. This medication history was used to estimate comorbidity with the number and types of medication used to quantify comorbid disease burden. Smoking status is recorded at each assessment and recorded as current, ex-smoker, or never smoker.

A joint examination is conducted and a blood sample is obtained for measurement of rheumatoid factor (RF) and C-reactive protein (CRP) concentration. Patients complete a modified Health Assessment Questionnaire (HAQ) at each assessment. Subjects with definite inflammatory synovitis, who are not subsequently diagnosed by a 
Table 1 Baseline variables by baseline NSAID use among patients with IP

\begin{tabular}{|c|c|c|c|}
\hline & $\begin{array}{l}\text { Not baseline NSAID } \\
\text { user } n=310, n(\%) \text { or } \\
\text { median (IOR) }\end{array}$ & $\begin{array}{l}\text { Baseline NSAID } \\
\text { user } n=613, n(\%) \\
\text { or median (IQR) }\end{array}$ & p Value \\
\hline \multicolumn{4}{|l|}{$\begin{array}{l}\text { Demographics and social } \\
\text { history: }\end{array}$} \\
\hline Age & 55 (41 to 69$)$ & 55 (42 to 66$)$ & 0.62 \\
\hline Female & $207(66.8)$ & $392(64.0)$ & 0.39 \\
\hline Lower social class $>3 \mathrm{~b}^{*}$ & $140(47.5)$ & $283(48.1)$ & 0.85 \\
\hline Ever smoker & $200(64.5)$ & $428(69.8)$ & 0.10 \\
\hline Current smoker & $88(28.4)$ & $165(26.9)$ & 0.64 \\
\hline \multicolumn{4}{|l|}{ Comorbid drug use: } \\
\hline 1-2 Comorbid conditions & $115(37.1)$ & $211(34.4)$ & 0.41 \\
\hline$\geqslant 3$ Comorbid conditions & $13(4.1)$ & $25(4.1)$ & 0.38 \\
\hline 1 CVD drug & $33(10.6)$ & $56(9.1)$ & 0.41 \\
\hline$\geqslant 2 \mathrm{CVD}$ drugs & $27(8.7)$ & $44(7.2)$ & 0.36 \\
\hline Aspirin & $17(2.8)$ & $14(4.5)$ & 0.19 \\
\hline $\begin{array}{l}\text { Antihypertensive } \\
\text { medication }\end{array}$ & $46(14.8)$ & $92(15.0)$ & 0.94 \\
\hline Heart failure medication & $53(17.1)$ & $91(14.9)$ & 0.61 \\
\hline IHD medication & $40(12.9)$ & 72 (11.8) & 0.85 \\
\hline $\begin{array}{l}\text { Diabetes medication } \\
\text { Inflammatory disease } \\
\text { variables: }\end{array}$ & $9(2.9)$ & $21(3.4)$ & 0.67 \\
\hline $\begin{array}{l}\text { Disease duration } \\
>6 \text { months }\end{array}$ & $163(52.6)$ & $305(49.8)$ & 0.42 \\
\hline $\begin{array}{l}\text { Morning stiffness } \\
\geqslant 60 \mathrm{~min}\end{array}$ & $104(33.5)$ & $257(41.9)$ & 0.01 \\
\hline Swollen joint count & $5(2$ to 11$)$ & $8(3$ to 14$)$ & $<0.01$ \\
\hline Tender joint count & $6(2$ to 14$)$ & 9 (3 to 19$)$ & $<0.01$ \\
\hline $\mathrm{CRP} \geqslant 5 \mathrm{mg} /$ litre & $133(42.9)$ & $350(57.1)$ & $<0.01$ \\
\hline $\begin{array}{l}\text { Rheumatoid factor } \\
\text { positive }\end{array}$ & $72(23.2)$ & $209(34.1)$ & $<0.01$ \\
\hline RA (by ACR criteria) & $128(41.3)$ & $324(52.9)$ & $<0.01$ \\
\hline Rheumatoid nodules & $17(5.5)$ & $58(9.5)$ & 0.04 \\
\hline $\mathrm{HAO}$ & $0.5(0.125$ to 1.25$)$ & $0.875(0.375$ to 1.5$)$ & $<0.01$ \\
\hline DMARDs & $44(14.2)$ & $110(17.9)$ & 0.14 \\
\hline Methotrexate & $2(0.7)$ & $12(2.0)$ & 0.21 \\
\hline Hydroxychloroquine & $2(0.65)$ & $5(0.82)$ & 0.78 \\
\hline Steroids & 37 (11.9) & $37(6.04)$ & $<0.01$ \\
\hline
\end{tabular}

*Social class only available for 880 patients.

ACR, American College of Rheumatology; CRP, C-reactive protein; CVD, cardiovascular disease; DMARD, disease-modifying antirheumatic drug; HAQ, Health Assessment Questionnaire; IHD, ischaemic heart disease; IQR, interquartile range; IP, inflammatory polyarthritis; NSAID, non-steroidal anti-inflammatory drug; RA, rheumatoid arthritis.

consultant rheumatologist to have another condition, apart from rheumatoid arthritis, psoriatic arthritis, postviral arthritis and undifferentiated inflammatory polyarthritis, are eligible for inclusion on the register and are followed longitudinally. Subsequent assessments occur annually for the first 5 years of the study. After this, assessments occur every 2 years.

\section{NSAID exposure}

NSAID use at the start of each interval of follow-up was determined from the current medication history obtained by the research nurse during each assessment. NSAID use prior to the baseline assessment was not recorded. NSAID exposure included OTC NSAIDs as well as doctor-prescribed NSAIDs. However, dosages, frequency and dates of starting and stopping NSAIDs were not recorded. Baseline NSAID use, ever reporting NSAID use in the study and time-varying NSAID exposure during the follow-up assessments were recorded. We did not record whether patients had been exposed to NSAIDs in the interim months between assessments.
Table 2 Mortality in patients with inflammatory polyarthritis

\begin{tabular}{lccc}
\hline & Men $(\mathbf{n}=\mathbf{3 2 4})$ & Women $(\mathbf{n}=\mathbf{5 9 9})$ & All $(\mathbf{n}=\mathbf{9 2 3})$ \\
\hline All causes, $\mathbf{n}(\%)$ & $108(33.3)$ & $95(15.9)$ & $203(22.0)$ \\
Cardiovascular, n (\%) & $44(13.6)$ & $41(6.8)$ & $85(9.2)$ \\
Respiratory, $\mathrm{n}(\%)$ & $16(4.9)$ & $12(2.0)$ & $28(3.0)$ \\
Neoplastic, $\mathrm{n}(\%)$ & $34(10.5)$ & $20(3.3)$ & $54(5.8)$
\end{tabular}

\section{Outcome measures}

All patients included on the register were flagged on the UK National Health Service Central Register. Death notification and death certificates were provided for study participants who died in the UK. The underlying cause of death was grouped according to the International Classification of Diseases, 9th revision (ICD-9) ${ }^{14}$ Death was attributed to CVD if the main cause of death was issued with ICD9 codes 393-459.

\section{Analysis}

Relationships between NSAID use and all cause and CVD mortality were explored using logistic regression. Mortality outcomes were explored in baseline NSAID users compared to non-NSAID users at baseline. Patients who were identified as never having used NSAIDs throughout the period of the study were compared to those patients who were identified as NSAID users at any NOAR assessments. Initially univariate analyses were undertaken. Subsequent analyses were undertaken by pooling data across all subjects and then adjusting for age and gender. Multivariate analyses were undertaken to determine the independent effect of NSAID use on all cause and cardiovascular mortality. The models were adjusted for gender, age and timevarying covariates recorded at the study assessments, including smoking status, CRP tertiles, RF, rheumatoid nodules, joint counts, morning stiffness, disability (HAQ), corticosteroids, DMARDs, number of comorbid medications used and use of medication to treat CVD. In addition NSAID use was treated as a time-varying exposure and the relationship between NSAID use and mortality was explored for each interval of follow-up. This was performed univariately and multivariately adjusting for time-varying covariates including disease variables, medication and smoking status. The analyses were repeated for the subgroup of patients who cumulatively met 1987 American College of Rheumatology (ACR) classification criteria for RA.

\section{RESULTS}

A total of 923 subjects recruited to NOAR between 1990 and 1994 were eligible for study. Complete mortality follow-up was obtained for the cohort up to the end of December 2003. The median follow-up period was 10.7 years (interquartile range (IOR) 9.4 to 12.2).

At the baseline assessment $613(66.4 \%)$ patients were NSAID users and a further $141(15.3 \%)$ patients were identified as using NSAIDS during the follow-up assessments. Of these 754 ever NSAID users, NSAID use was reported at the start of $58 \%$ of follow-up intervals. A total of $169(18.3 \%)$ patients reported no NSAID exposure at any of the study assessments. The mean duration of NSAID exposure during the period of this study, estimated from the number of study assessments where NSAID use was reported, was 4 years.

Baseline demographic and clinical disease characteristics of the cohort stratified by baseline NSAID use are shown in table 1 . The median age at disease onset was 55 years in NSAID users and non-users, and the proportion of female patients was similar in both groups. Approximately two-thirds of the 
subjects were or had been smokers. Comorbid illness, determined by current drug use, was remarkably similar between NSAID users and non-users with approximately 1 in 10 taking a cardiovascular drug at disease entry. Patients who were using NSAIDs had markers of more severe inflammatory joint disease at baseline. NSAID users were more likely to be RF positive, have rheumatoid nodules and a higher HAQ score at baseline. They also had higher CRP concentrations and had clinical evidence of more active inflammatory joint disease with higher swollen and tender joint counts, and more prolonged morning stiffness than non-NSAID users. DMARD use at baseline was low and similar in both groups. At baseline $41 \%$ of the cohort met ACR classification criteria for RA. This rose to $67 \%$ when the criteria were applied cumulatively throughout the study.

During the period under study only 41 patients were treated with selective COX2 inhibitors at any time. This exposure was limited to the last 2 years of the study period. During the study, diclofenac was used most frequently, identified in $27 \%$ of the NSAID exposures during the study, followed by naproxen $17 \%$ and ibuprofen $17 \%$. Other less frequently used drugs included ketoprofen, indomethacin, piroxicam, meloxicam and nabumetone. Switching between NSAIDs was frequently observed during the follow-up period.

Patients were followed up to the end of 2003 with a median follow-up period of 10.1 years (interquartile range 9.3 to 10.8). Over this time period there were 203 deaths (table 2). Approximately twice the proportion of males died as females. Cardiovascular disease was identified as the underlying cause of death in 85 participants.

The univariate relationship between NSAID exposure and subsequent all-cause and cardiovascular mortality by gender is shown in table 3. There was a trend for baseline NSAID use to be associated with reduced all cause and CVD mortality. Patients who ever used NSAIDs during the study had a lower risk of death than non-NSAID users (odds ratio (OR) 0.62) and this was most marked for CVD mortality (OR 0.48). Figure 1 demonstrates the Kaplan Meier survival estimates for cardiovascular mortality by ever use of NSAIDs. Time-varying NSAID exposure was explored univariately and a similar inverse relationship was observed with all cause mortality (OR 0.58) and CVD mortality (OR 0.51).

The multivariate analyses are shown in table 4. The final models examining the association between NSAID use and all cause mortality were adjusted for gender and time-varying covariates for each interval of follow-up. Baseline NSAID use (adjusted $\mathrm{OR}\left(\mathrm{OR}_{\mathrm{adj}}\right) 0.62,95 \% \mathrm{CI} 0.45$ to 0.84$)$ and ever use of NSAIDs (OR adj $0.52,95 \%$ CI 0.36 to 0.76$)$ were associated with reduced risk of all cause mortality. Baseline NSAID use was

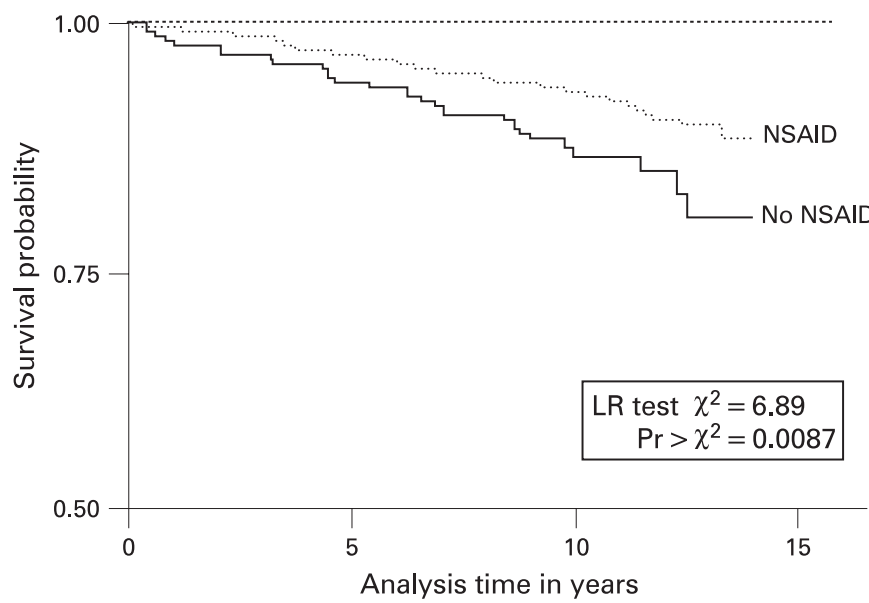

Figure 1 Cardiovascular mortality: Kaplan-Meier survival estimates, by ever use of non-steroidal anti-inflammatory drug (NSAID).

associated with reduced risk of CVD mortality $\left(\mathrm{OR}_{\mathrm{adj}}\right.$ 0.54, 95\% CI 0.34 to 0.86 ). Ever use of NSAIDs during follow-up was also significantly associated with a reduced risk of CVD mortality (adjusted hazard ratio $\left(\mathrm{HR}_{\mathrm{adj}}\right)$ 0.38, 95\% CI 0.23 to 0.66$)$. Timevarying NSAID exposure was associated with a trend for reduced all cause mortality (OR $0.72,95 \%$ CI 0.52 to 1.00$)$ and CVD mortality (OR $0.66,95 \%$ CI 0.40 to 1.09 ) during each interval of follow-up, but neither reached statistical significance. Repeating the analyses in the subgroup of patients with RA did not reveal differences to that in the IP cohort.

In secondary analyses NSAID exposure was examined to explore whether increasing duration of NSAID exposure was associated with reduced CVD mortality. The duration of NSAID exposure covariate was entered into the multivariate logistic model predicting CVD mortality. Longer duration of NSAID use was not associated with a significant reduction in CVD mortality risk in those patients exposed to NSAIDs during this study (OR 1.0, 95\% CI 0.86 to 1.15) for each additional period of NSAID exposure.

To assess the possibility that the association between NSAIDs and mortality was mediated by confounding, we explored baseline covariates associated with use of NSAIDs during the study. Variables associated with more severe disease, including RF, DMARDs, elevated CRP and swollen joint counts, were found to be independently associated with use of NSAIDs in multivariate logistic models (table 5). There was an inverse association between use of corticosteroid medication and NSAID use (OR $0.44,95 \%$ CI 0.35 to 0.55 ), but corticosteroids

Table 3 Univariate analysis predicting all cause and cardiovascular disease mortality

\begin{tabular}{|c|c|c|c|c|c|c|c|}
\hline & \multirow[b]{2}{*}{ Patients } & \multirow[b]{2}{*}{$\mathbf{n}$} & \multirow[b]{2}{*}{$\begin{array}{l}\text { Person time } \\
\text { intervals }\end{array}$} & \multicolumn{2}{|l|}{ All cause mortality } & \multicolumn{2}{|l|}{ CVD mortality } \\
\hline & & & & $\begin{array}{l}\text { Univariate, } \\
\text { OR (95\% CI) }\end{array}$ & $\begin{array}{l}\text { Adjusted age and gender, } \\
\text { OR (95\% CI) }\end{array}$ & $\begin{array}{l}\text { Univariate, } \\
\text { OR (95\% CI) }\end{array}$ & $\begin{array}{l}\text { Adjusted age and gender, } \\
\text { OR (95\% CI) }\end{array}$ \\
\hline \multirow{2}{*}{$\begin{array}{l}\text { Baseline } \\
\text { NSAID use }\end{array}$} & All & 923 & 5634 & 0.73 (0.55 to 0.99$)$ & $0.81(0.60$ to 1.03$)$ & 0.67 (0.43 to 1.04$)$ & $0.73(0.48$ to 1.15$)$ \\
\hline & Males & 324 & 1892 & 0.61 (0.41 to 0.92$)$ & $0.74(0.50$ to 1.12$)$ & 0.79 (0.42 to 1.47$)$ & 0.94 (0.50 to 1.78$)$ \\
\hline \multirow{2}{*}{$\begin{array}{l}\text { Ever NSAID } \\
\text { use }\end{array}$} & All & 923 & 5634 & 0.62 (0.44 to 0.86$)$ & $0.70(0.50$ to 1.00$)$ & $0.48(0.29$ to 0.77$)$ & $0.54(0.33$ to 0.88$)$ \\
\hline & Females & 599 & 3742 & 0.74 (0.44 to 1.22 ) & 0.81 (0.48 to 1.36$)$ & $0.42(0.22$ to 0.82$)$ & $0.46(0.23$ to 0.90$)$ \\
\hline \multirow{2}{*}{$\begin{array}{l}\text { Time-varying } \\
\text { NSAID use }\end{array}$} & Females & 599 & 3742 & $0.60(0.39$ to 0.91$)$ & $0.68(0.44$ to 1.05$)$ & $0.50(0.26$ to 0.97$)$ & $0.58(0.30$ to 1.12$)$ \\
\hline & Males & 324 & 1892 & $0.54(0.36$ to 0.81$)$ & $0.65(0.43$ to 0.98$)$ & $0.51(0.27$ to 0.94$)$ & $0.59(0.31$ to 1.12$)$ \\
\hline
\end{tabular}

CVD, cardiovascular disease; NSAID, non-steroidal anti-inflammatory drug; OR, odds ratio. 
Table 4 Multivariate analysis: predicting all cause and cardiovascular disease mortality

\begin{tabular}{lllll}
\hline & & $\begin{array}{l}\text { Number of person } \\
\text { time intervals, } \mathbf{n}\end{array}$ & $\begin{array}{l}\text { All cause mortality, } \\
\text { adjusted } \mathbf{O R} \text { (95\% Cl) }\end{array}$ & $\begin{array}{l}\text { CVD mortality, adjusted } \\
\text { OR (95\% Cl) }\end{array}$ \\
\hline Baseline NSAID & All IP & 5634 & $0.62(0.45$ to 0.84$)$ & $0.54(0.34$ to 0.86$)$ \\
Ever NSAID & RA & 3791 & $0.65(0.45$ to 0.93$)$ & $0.69(0.39$ to 1.20$)$ \\
& All IP & 5634 & $0.52(0.36$ to 0.76$)$ & $0.38(0.23$ to 0.66$)$ \\
Time-varying NSAID use & RA & 3791 & $0.61(0.38$ to 0.98$)$ & $0.53(0.27$ to 1.06$)$ \\
& All IP & 5634 & $0.72(0.52$ to 1.00$)$ & $0.66(0.40$ to 1.09$)$ \\
& RA & 3791 & $0.75(0.52$ to 1.08$)$ & $0.86(0.49$ to 1.49$)$
\end{tabular}

\begin{abstract}
RA status refers to cumulative RA status by the sixth assessment. Final multivariate model adjusted for time-varying age, gender, $\mathrm{RF}$, RA status, nodules, tertiles of swollen and tender joint counts, CRP, HAQ, number of medications other than arthritis medication, number of CVD medications, corticosteroid use, methotrexate use and other DMARD use, smoking history

CRP, C-reactive protein; CVD, cardiovascular disease; DMARD, disease-modiftying antirheumatic drug; HAQ, Health Assessment Questionnaire; NSAID, non-steroidal anti-inflammatory drug; OR, odds ratio; IP, inflammatory polyarthritis; RA, rheumatoid arthritis; $\mathrm{RF}$, rheumatoid factor.
\end{abstract}

were not associated with all cause mortality or CVD mortality in the multivariate models. Use of drugs to treat CVD comorbidity was inversely associated with NSAID use.

A sensitivity analysis was conducted to explore the strength of residual confounding that would be required to explain the observed association between non-NSAID use and CVD mortality. ${ }^{15}$ Avoidance of NSAIDs, observed in $18 \%$ of this cohort, was associated with CVD mortality $\left(\mathrm{OR}_{\text {adj }} 2.6,95 \% \mathrm{CI}\right.$ 1.5 to 4.3). If we assume a prevalence of the unmeasured confounder is $20 \%$, a single residual confounder would have to have to be very strongly associated with NSAID avoidance (OR 4.0) and cardiovascular mortality (relative risk 4.0) to reduce the lower CI value from 1.5 to 1.0. It is difficult to think of potential confounders that might have such strong associations with NSAID avoidance and CVD mortality.

\section{CONCLUSIONS}

In this cohort of patients with early IP, NSAID use was not found to be associated with increased risk of all cause mortality or cardiovascular mortality. Patients who were exposed to NSAIDs tended to have a reduced risk of dying than the study patients who did not receive NSAIDs. This relationship was particularly strong for cardiovascular mortality and, ever being exposed to NSAIDs was associated with a 2.5-fold reduction in risk of cardiovascular death. However, increasing duration of NSAID exposure was not found to be associated with greater reductions in CVD mortality.

These findings are somewhat surprising given the results from other studies. Several clinical trials have demonstrated a higher risk of adverse CVD outcomes for patients treated with selective COX2 inhibitors compared to placebo. ${ }^{11}{ }^{16-18}$ In addition, epidemiological studies have raised concerns over the cardiovascular safety of non-selective NSAIDs. ${ }^{19-22}$ These studies examined cardiovascular outcomes in large population based

Table 5 Multivariate analysis: baseline predictors of NSAID use during study

\begin{tabular}{ll}
\hline & $\mathbf{O R}(\mathbf{9 5} \% \mathbf{C I})$ \\
\hline Swollen joint count//tertiles) & $1.15(1.08$ to 1.23$)$ \\
RF positive & $1.53(1.35$ to 1.73$)$ \\
Use of DMARDs & $1.39(1.20$ to 1.61$)$ \\
CRP (tertile) & $1.13(1.06$ to 1.21$)$ \\
Use of any CVD drugs & $0.66(0.57$ to 0.77$)$ \\
Steroid use & $0.44(0.35$ to 0.55$)$
\end{tabular}

CRP, C-reactive protein; CVD, cardiovascular disease; DMARD, disease-modifying antirheumatic drug; NSAID, non-steroidal anti-inflammatory drug; OR, odds ratio; $\mathrm{RF}$, rheumatoid factor. groups. There is little data reported on NSAID associations with cardiovascular events within cohorts of patients with chronic inflammatory disease. A small cardioprotective effect has been observed in some studies with use of naproxen ${ }^{911}$ and ibuprofen. ${ }^{23}$ A recent meta-analysis of nine randomised controlled trials in patients with osteoarthritis and rheumatoid arthritis found that use of non-selective NSAIDs, compared to placebo, had a combined odds ratio for CVD events of 0.6 ( $95 \%$ CI 0.2 to 1.7) ${ }^{24}$ Naproxen use was associated with similar risk of CVD events to that observed with other non-selective NSAIDs. The number of events reported by these studies was low and the authors conclude that use of NSAIDs had no significant effect on cardiovascular events in patients with joint disease. ${ }^{24}$ Therefore our finding of reduced risk of CVD mortality in patients with inflammatory arthritis using NSAIDs warrants further discussion.

Inflammation is a strong predictor of future CVD mortality in early $\mathrm{IP}^{25}$ and in RA. ${ }^{36}$ In this study markers of inflammation, including joint counts and baseline CRP, were higher in patients who used NSAIDs. However, there were no significant interactions between NSAID use and baseline CRP concentration in the multivariate regression models.

We know that inflammation is associated with modification of eicosanoids with increased generation of thromboxane A2 and prostacyclin. COX1 derived thromboxane A2 promotes platelet aggregation and vasoconstriction while COX2 driven endothelial prostacyclin production reduces the effects of thromboxane A2 by triggering vasodilatation and inhibiting platelet aggregation. ${ }^{27}$ Atherosclerotic lesions are rich in cells that express the COX2 enzyme that may be implicated in atherosclerotic plaque destabilisation and the development of CVD events. ${ }^{28}$ It is possible that the use of NSAIDs in patients with chronic inflammation influences the eicosanoid pathway to produce a net beneficial effect on the cardiovascular system. In our study we failed to show any further CVD benefit from increasing duration of NSAID exposure. This suggests that NSAID-induced eiconanoid modification was unlikely to be responsible for the favourable CVD mortality outcome. A limitation of this study was that NSAID exposure was not accurately measured as dosage and actual time on each treatment were not recorded. Therefore it is difficult to interpret whether increased NSAID exposure actually influences CVD mortality.

In clinical trials it has been demonstrated that regular use of high-dose naproxen induces suppression of platelet thromboxane similar to that seen with low-dose aspirin, ${ }^{29}$ and this lends plausibility to a cardioprotective effect of this drug. Other nonselective NSAIDs may have similar antiplatelet effects to 
aspirin. ${ }^{30}$ However, population based observational studies have failed to show cardioprotective effects of these drugs. ${ }^{31}$ NSAIDs tend to be used regularly in the treatment of symptoms of inflammatory arthritis. However, dosage and frequency of NSAIDs were not recorded in this study and many patients changed NSAIDs during follow-up. Naproxen was used in only $17 \%$ of NSAID exposures identified and it seems unlikely that the cardioprotective association observed in this study was due to an effect of naproxen alone. The most frequently used NSAID during the period of this study was diclofenac, which has been shown in other studies to have a CVD risk similar to that seen with selective COX2 inhibitors. ${ }^{32} 33$

A major limitation of this study was the potential inaccuracy in assigning NSAID exposure. It is highly likely that several patients, categorised as "never" exposed to NSAIDs during this study, will have used NSAIDs either prior to their baseline assessment or during the interim period between their assessments. In the UK, patients with chronic inflammatory arthritis are often encouraged to use NSAIDs for symptom control. It is likely that frequent users of NSAIDs will include NSAIDs in their current medication that is recorded by the nurses conducting the home-based interviews. Therefore, although NSAID exposures were not recorded accurately in this observational study, the finding of higher death rates in patients with IP who do not frequently use NSAIDs is an important study finding that contributes to the research literature in this area. This should prompt further study examining NSAID associations with CVD outcomes in inflammatory arthritis.

Another possible explanation for our findings includes the effects of unmeasured confounders. This longitudinal study has enabled examination of the effects of NSAID exposure on mortality with adjustment for variables measuring the severity of the inflammatory joint disease, inflammation, smoking and comorbidity. However, unmeasured factors may have influenced the decision to use an NSAID and the risk of mortality. The sensitivity analysis revealed that a single unmeasured confounder would have to be very strongly associated with NSAID use and mortality. It is possible that multiple unmeasured confounders may act together to produce this size of effect. Patient characteristics that are difficult to quantify, for example frailty, may have led to avoidance of NSAID use in these patients. In this situation NSAID use might indicate more healthy participants who have better CVD survival.

Doctor prescribing habits are difficult to determine. At the time of this study there was little evidence to suggest that NSAIDs should be avoided in patients at high risk of CVD. Therefore, it is unlikely that doctors systematically avoided NSAID prescriptions for patients with increased CVD risk. Another limitation of this study was that comorbidity was not recorded. However, CVD medication, antiplatelet medication and cholesterol lowering medication were recorded at the baseline and annual assessments and this provided a proxy measure for CVD comorbidity. In the propensity model (table 5), CVD medication use was identified as having an inverse association with NSAID use. This might support doctor-channeling of NSAIDs away from frail patients with CVD thereby explaining this paradoxical relationship between NSAID use and reduced CVD mortality outcome. However, the multivariate analysis revealed that the NSAID mortality association persisted even after adjusting for CVD medication use.

Therefore the finding of reduced CVD mortality in patients with IP treated with NSAIDs is interesting but difficult to explain. It may represent channeling of NSAIDs away from vulnerable patients rather than a true cardioprotective effect of the NSAID drug. However, this study suggests that the increased CVD risk observed in patients with IP is unlikely to be due to the effects of NSAIDs.

Funding: The Norfolk Arthritis Register is funded by the Arthritis Research Campaign.Ethics approval: Ethics approval was obtained.

Competing interests: None.

\section{REFERENCES}

1. Solomon DH, Karlson EW, Rimm EB, Cannuscio CC, Mandl LA, Manson JE, et al. Cardiovascular morbidity and mortality in women diagnosed with rheumatoid arthritis Circulation 2003;107:1303-7

2. Maradit-Kremers H, Crowson CS, Nicola PJ, Ballman KV, Roger VL, Jacobsen SJ, et al. Increased unrecognized coronary heart disease and sudden deaths in rheumatoid arthritis: a population-based cohort study. Arthritis Rheum 2005:52:402-11.

3. Maradit-Kremers H, Nicola PJ, Crowson CS, Ballman KV, Gabriel SE. Cardiovascular death in rheumatoid arthritis: a population-based study. Arthritis Rheum 2005; 52:722-32.

4. Suissa S, Bernatsky S, Hudson M. Antirheumatic drug use and the risk of acute myocardial infarction. Arthritis Care Res 2006;55:531-6.

5. van Halm V, Nurmohamed M, Twisk J, Dijkmans B, Voskuyl A. Disease-modifying antirheumatic drugs are associated with a reduced risk for cardiovascular disease in patients with rheumatoid arthritis: a case control study. Arthritis Res Ther 2006;8:R151

6. Choi HK, Hernan MA, Seeger JD, Robins JM, Wolfe F. Methotrexate and mortality in patients with rheumatoid arthritis: a prospective study. Lancet 2002;359:1173-7.

7. Armstrong EP, Malone DC. The impact of nonsteroidal anti-inflammatory drugs on blood pressure, with an emphasis on newer agents. Clin Ther 2003;25:1-18.

8. Bleumink GS, Feenstra J, Sturkenboom MC, Stricker BH. Nonsteroidal antiinflammatory drugs and heart failure. Drugs 2003:63:525-34.

9. Watson DJ, Rhodes T, Cai B, Guess HA. Lower risk of thromboembolic cardiovascular events with naproxen among patients with rheumatoid arthritis. Arch Intern Med 2002;162:1105-10.

10. Bombardier C, Laine L, Reicin A, Shapiro D, Burgos-Vargas R, Davis B, et al. Comparison of upper gastrointestinal toxicity of rofecoxib and naproxen in patients with rheumatoid arthritis. VIGOR Study Group. N Engl J Med 2000;343:1520-8.

11. Juni P, Nartey L, Reichenbach S, Sterchi R, Dieppe PA, Egger M. Risk of cardiovascular events and rofecoxib: cumulative meta-analysis. Lancet 2004;364:2021-9.

12. McGettigan PM, Henry DMCF. cardiovascular risk and inhibition of cyclooxygenase: a systematic review of the observational studies of selective and nonselective inhibitors of cyclooxygenase 2. JAMA 2006;296:1633-44.

13. Symmons DP, Barrett EM, Bankhead CR, Scott DG, Silman AJ. The incidence of rheumatoid arthritis in the United Kingdom: results from the Norfolk Arthritis Register Br J Rheumatol 1994;33:735-9.

14. World Health Organization. International classification of diseases, 9th revision Geneva, Switzerland: World Health Organisation, 1977.

15. Schneeweiss S. Sensitivity analysis and external adjustment for unmeasured confounders in epidemiologic database studies of therapeutics. Pharmacoepidemiol Drug Safety 2006;15:291-303.

16. Bertagnolli MM, Eagle CJ, Zauber AG, Redston M, Solomon SD, Kim K, et al. Celecoxib for the prevention of sporadic colorectal adenomas. N Engl J Med 2006;355:873-84.

17. Bresalier RS, Sandler RS, Quan H, Bolognese JA, Oxenius B, Horgan K, et al. Cardiovascular events associated with rofecoxib in a colorectal adenoma chemoprevention trial. N Engl J Med 2005;352:1092-102

18. Nussmeier NA, Whelton AA, Brown MT, Langford RM, Hoeft A, Parlow JL, et al Complications of the COX-2 inhibitors parecoxib and valdecoxib after cardiac surgery. N Engl J Med 2005;352:1081-91.

19. Hippisley-Cox J, Coupland C. Risk of myocardial infarction in patients taking cyclooxygenase-2 inhibitors or conventional non-steroidal anti-inflammatory drugs: population based nested case-control analysis. BMJ 2005;330:1366.

20. Johnsen SP, Larsson H, Tarone RE, McLaughlin JK, Norgard B, Friis S, et al. Risk of hospitalization for myocardial infarction among users of rofecoxib, celecoxib, and other NSAIDs - a population-based case-control study. Arch Intern Med 2005; 165:978-84

21. Chan AT, Manson JE, Albert CM, Chae CU, Rexrode KM, Curhan GC, et al. Nonsteroidal antiinflammatory drugs, acetaminophen, and the risk of cardiovascula events. Circulation 2006;113:1578-87.

22. Gislason GH, Jacobsen S, Rasmussen JN, Rasmussen S, Buch P, Friberg J, et al Risk of death or reinfarction associated with the use of selective cyclooxygenase-2 inhibitors and nonselective nonsteroidal antïnflammatory drugs after acute myocardial infarction. Circulation 2006;113:2906-13.

23. Ko D, Wang Y, Berger AK, Radford MJ, Krumholz HM. Nonsteroidal antiinflammatory drugs after acute myocardial infarction. Am Heart J 2002;143:475-81.

24. Salpeter SR, Gregor P, Ormiston TM, Whitlock R, Raina P, Thabane L, et al. Meta analysis: cardiovascular events associated with nonsteroidal anti-inflammatory drugs. Am J Med 2006;119:552-9. 
25. Goodson NJ, Symmons DPM., Scott DGI., Bunn D, Lunt M, Silman AJ. Baseline Creactive protein and prediction of death from cardiovascular disease in patients with inflammatory polyarthritis. Arthritis Rheum 2005;52:2293-9.

26. Jacobsson LT, Turesson C, Hanson RL, Pillemer S, Sievers ML, Pettitt DJ, et al. Joint swelling as a predictor of death from cardiovascular disease in a population study of Pima Indians. Arthritis Rheum 2001;44:1170-6.

27. Spektor G, Fuster V. Drug insight: cyclo-oxygenase 2 inhibitors and cardiovascular risk - where are we now? Nat Clin Pract Cardiovasc Med 2005;2:290-300.

28. Paramo JA, Rodriguez JA, Beloqui 0, Orbe J. Monocyte cyclooxygenase-2 activity: a new therapeutic target for atherosclerosis?. Curr Drug Targets Cardiovasc Haematol Disord 2005;5:303-11.

29. Capone ML, Tacconelli S, Sciulli MG, Grana M, Ricciotti E, Minuz P, et al. Clinical pharmacology of platelet, monocyte, and vascular cyclooxygenase inhibition by naproxen and low-dose aspirin in healthy subjects. Circulation 2004;109:1468-71.
30. Rothschild BM. Comparative antiplatelet activity of COX1 NSAIDS versus aspirin, encompassing regimen simplification and gastroprotection: a call for a controlled study. Reumatismo 2004;56:89-93.

31. Solomon DH, Glynn RJ, Levin R, Avorn J. Nonsteroidal anti-inflammatory drug use and acute myocardial infarction. Arch Intern Med 2002;162:1099-104.

32. Kearney PM, Baigent C, Godwin J, Halls H, Emberson JR, Patrono C. Do selective cyclo-oxygenase-2 inhibitors and traditional non-steroidal anti-inflammatory drugs increase the risk of atherothrombosis? Meta-analysis of randomised trials. BMJ 2006;332:1302-8.

33. Cannon CP, Curtis SP, FitzGerald GA, Krum H, Kaur A, Bolognese JA, et al. Cardiovascular outcomes with etoricoxib and diclofenac in patients with osteoarthritis and rheumatoid arthritis in the Multinational Etoricoxib and Diclofenac Arthritis Long-term (MEDAL) programme: a randomised comparison. Lancet 2006;368:1771-81.

\section{Submit an eLetter, and join the debate}

eLetters are a fast and convenient way to register your opinion on topical and contentious medical issues. You can find the "submit a response" link alongside the abstract, full text and PDF versions of all our articles. We aim to publish swiftly, and your comments will be emailed directly to the author of the original article to allow them to respond. eLetters are a great way of participating in important clinical debates, so make sure your voice is heard. 